\title{
Nitric oxide provides myocardial protection when added to the cardiopulmonary bypass circuit during cardiac surgery: Randomized trial
}

Nikolay O. Kamenshchikov, MD, ${ }^{\mathrm{a}}$ Irina A. Mandel, MD, PhD, ${ }^{\mathrm{b}, \mathrm{c}}$ Yuriy K. Podoksenov, MD, PhD, ${ }^{\mathrm{a}, \mathrm{d}}$ Yulia S. Svirko, MD, PhD, ${ }^{\text {,d }}$ Vladimir V. Lomivorotov, MD, PhD, ${ }^{\mathrm{e}}$ Sergey L. Mikheev, MD, PhD, Boris N. Kozlov, MD, PhD, ${ }^{\mathrm{a}, \mathrm{d}}$ Vladimir M. Shipulin, MD, PhD, ${ }^{\mathrm{a}, \mathrm{d}}$ Aleksandra A. Nenakhova, MA, ${ }^{\mathrm{a}}$ and Yana J. Anfinogenova, $\mathrm{PhD}^{\mathrm{a}, \mathrm{g}}$

\section{ABSTRACT}

Objectives: The aim of this pilot study was to elucidate the effects of exogenous nitric oxide (NO) supply to the extracorporeal circulation circuit for cardioprotection against ischemia-reperfusion injury during coronary artery bypass grafting (CABG) with cardiopulmonary bypass (CPB).

Methods: A total of 60 patients with coronary artery disease scheduled for CABG with CPB were enrolled in a prospective randomized study. Patients were allocated randomly to receive treatment according to standard or modified CPB protocol where 40-ppm NO was added to the $\mathrm{CPB}$ circuit during cardiac surgery. The primary endpoint was the measurement of cardiac troponin I (cTnI). The secondary end points consisted in the measurements of creatine kinase-muscle/brain fraction (CK-MB) and vasoactive inotropic score (VIS).

Results: NO delivered into the CPB circuit had a cardioprotective effect. The level of cTnI was significantly lower in NO-treated group compared with the control group 6 hours after surgery: $1.79 \pm 0.39 \mathrm{ng} / \mathrm{mL}$ versus $2.41 \pm 0.55 \mathrm{ng} / \mathrm{mL}$, respectively $(P=.001)$. The CK-MB value was significantly lower in NOtreated group compared with the control group 24 hours after surgery: $47.69 \pm 8.08 \mathrm{U} / \mathrm{L}$ versus $62.25 \pm 9.78 \mathrm{U} / \mathrm{L}$, respectively $(P=.001)$; and the VIS was significantly lower in the NO-treated group 6 hours after the intervention.

Conclusions: NO supply to the CPB circuit during CABG exerted a cardioprotective effect and was associated with lower levels of VIS and cardiospecific blood markers cTnI and CK-MB. (J Thorac Cardiovasc Surg 2019;157:2328-36)

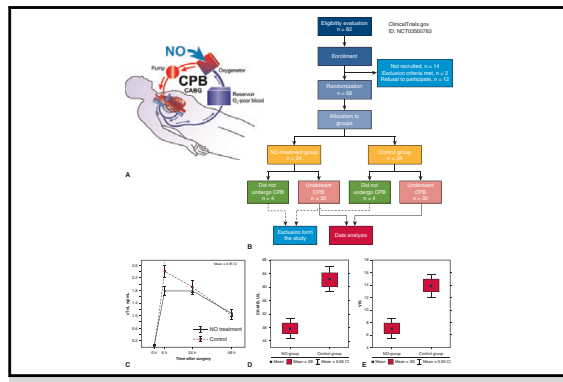

Nitric oxide supply to the cardiopulmonary bypass circuit during cardiac surgery.

\section{Central Message}

Nitric oxide supply to the cardiopulmonary bypass circuit during cardiac surgery is cardioprotective and is associated with lower levels of cardiac biomarkers and improved vasoactive inotropic score.

\section{Perspective}

This pilot study focused on the cardiac biomarkers and vasoactive inotropic score in patients administered with nitric oxide (NO) supplied to the cardiopulmonary bypass (CPB) circuit during cardiac surgery. NOmediated cardioprotection may improve clinical outcomes of cardiac and noncardiac surgery with $\mathrm{CPB}$. Larger studies on optimal duration and titration dose of $\mathrm{NO}$ treatment in $\mathrm{CPB}$ are encouraged.

See Commentaries on page 2337 and 2339.
From the ${ }^{\mathrm{a}}$ Cardiology Research Institute, Tomsk National Research Medical Center, Russian Academy of Sciences, Tomsk, Russia; ${ }^{b}$ Federal State Autonomous Educational Institution of Higher Education I. M. Sechenov First Moscow State Medical University of the Ministry of Health of the Russian Federation (Sechenov University), Moscow, Russia; ${ }^{c}$ Federal Research and Clinical Center for Specialized Medical Care and Medical Technologies, Federal Medico-Biological Agency, Moscow, Russia; ${ }^{\mathrm{d}}$ Siberian State Medical University, Tomsk, Russia; ${ }^{\mathrm{e}}$ E. Meshalkin National Medical Research Center, Novosibirsk, Russia; ${ }^{\mathrm{f}}$ Federal State Autonomous Institution "Treatment and Rehabilitation Center" of the Ministry of Healthcare of the Russian Federation, Moscow, Russia; and ${ }^{\mathrm{g}}$ National Research Tomsk Polytechnic University, Tomsk, Russia.

\footnotetext{
This work was supported, in part, by the Russian State Project "Science" (grant number AAAA-A15-115123110026-3). The paper was written within the framework of Tomsk Polytechnic University Competitiveness Enhancement Program grant. Received for publication April 18, 2018; revisions received Aug 8, 2018; accepted for publication Aug 25, 2018; available ahead of print Nov 15, 2018.

Address for reprints: Nikolay O. Kamenshchikov, MD, Cardiology Research Institute, Tomsk NRMC, 111a Kievskaya St, Tomsk, 634012, Russian Federation (E-mail: Nikolajkamenof@mail.ru).

$0022-5223 / \$ 36.00$

Copyright (c) 2018 by The American Association for Thoracic Surgery

https://doi.org/10.1016/j.jtcvs.2018.08.117
} 

Abbreviations and Acronyms
$\mathrm{CABG}=$ coronary artery bypass grafting
$\mathrm{CK}-\mathrm{MB}=$ creatine kinase-muscle/brain fraction
$\mathrm{CPB}=$ cardiopulmonary bypass
$\mathrm{cTnI}=$ cardiac troponin I
$\mathrm{FiO}_{2}=$ fraction of inspired oxygen
$\mathrm{NO}=$ nitric oxide
VIS $=$ vasoactive inotropic score

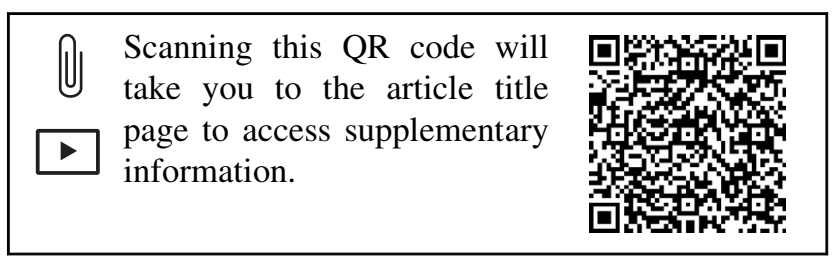

Despite the use of cardioplegia for myocardial protection, aortic clamping during cardiopulmonary bypass (CPB) may lead to ischemia-reperfusion injury, which is the main cause of complications and mortality in coronary artery bypass grafting (CABG). ${ }^{1}$ Clinical manifestations of this complication vary considerably, ranging from transient myocardial dysfunction to low cardiac output syndrome and circulatory shock. Postischemic contractile dysfunction, known as myocardial stunning, occurs in as many as $45 \%$ of patients after cardiac surgery. ${ }^{1} \mathrm{Up}$ to one quarter of patients who undergo CABG require inotropic support. ${ }^{2}$ Even in conditions of adequate myocardial revascularization, it may take time to restore cardiac function. Perioperative myocardial infarction occurs in 3\% to $30 \%$ of CABG. This increases the length of hospital stay and is the leading cause of hospital and long-term mortality and morbidity in this cohort of patients. ${ }^{3}$ Cardiac troponin I (cTnI) is considered a serum biomarker of myocyte necrosis following ischemia-reperfusion injury. Concentration of cTnI 20 hours after surgery is an independent predictor of hospital mortality, whereas elevated concentration of $\mathrm{cTnI}$ is associated with cardiac death. ${ }^{4}$

There is evidence that nitric oxide (NO) and its signaling pathway play an essential role in the mechanisms of cardioprotection in ischemia-reperfusion injury. ${ }^{5}$ In the hibernating myocardium, $\mathrm{NO}$ signaling induces neovascularization and improves functional reserve. ${ }^{6,7}$ Correction of myocardial stunning occurs in patients with cardiac arrest administered with NO donors, improving cardiac function and cardiac output additionally to direct vasodilation of coronary arteries. ${ }^{8}$ Proinflammatory cytokines are reduced in patients undergoing $\mathrm{CABG}$ treated with the $\mathrm{NO}$ donor sodium nitroprusside. ${ }^{8}$ The inhalation of 40 or $80 \mathrm{ppm}$ of NO decreases the infarct size and improves the cardiac function after myocardial ischemia-reperfusion injury. ${ }^{9}$

Gianetti and colleagues ${ }^{10}$ found that the peak levels of creatine kinase-muscle/brain fraction (CK-MB) are significantly lower in the group with inhaled NO compared with a control group 24 hours after cardiac surgery. There is evidence that delivery of NO to the oxygenator gas flow during pediatric CPB is accompanied by cardioprotective effects involving a reduction of troponin I and B-type natriuretic peptide levels in the postoperative period. ${ }^{11}$ This reduces the incidence of low cardiac output syndrome by varying degrees depending on patient age and surgical complexity. ${ }^{12}$

The aim of our study was to test the hypothesis that administration of NO during CPB is associated with significant decreases in the levels of cardiospecific biomarkers (cTnI and CK-MB) and subsequent improvement of cardiac function after surgery (Video 1).

\section{METHODS}

Study protocol was approved by the institutional review board of Cardiology Research Institute (approval no. 133 from May 15, 2015) and completed on November 30, 2016. The study received federal funding, and the Funding Agency was not involved in the interpretation of data. The study has been registered at ClinicalTrials.gov (ID: NCT03500783). All patients provided written informed consent for participation in the study and publication of the treatment outcomes. The study comprised 60 patients (46 men, 14 women), who underwent planned primary CABG with CPB (Figure 1 and Online Data Supplement) in the clinic of Cardiology Research Institute, Tomsk National Research Medical Center. Exclusion criteria were nonelective surgery, age older than 70 years, left ventricular ejection fraction less than $35 \%$, history of myocardial infarction within 3 months before surgery, chronic atrial fibrillation, diabetes mellitus, and the elevated levels of cardiac specific markers within 12 hours before the intervention.

Patients were divided into 2 groups: the NO-treated group received $40 \mathrm{ppm}$ of $\mathrm{NO}$ into the extracorporeal circulation line during $\mathrm{CPB}$ and the control group received standard $\mathrm{CPB}$. Considering NO dilution at a ratio of $1 / 25,000$ in the $\mathrm{CPB}$ circuit, no inert gas supply to the CPB circuit

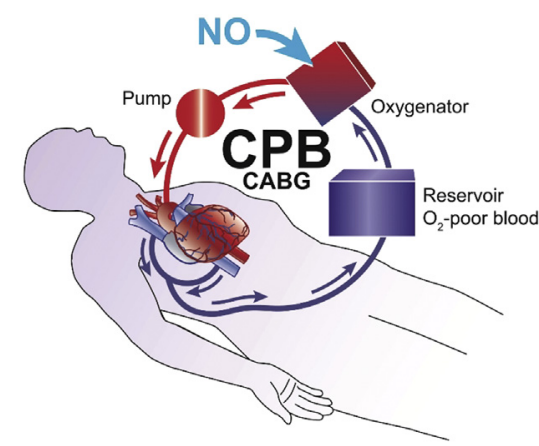

VIDEO 1. The video provides a brief introduction to the study showing that nitric oxide provides myocardial protection when added to the cardiopulmonary bypass circuit during cardiac surgery based on results of a randomized trial. Video available at: https://www.jtcvs.org/article/S0022-5223(18) 32614-X/fulltext. 


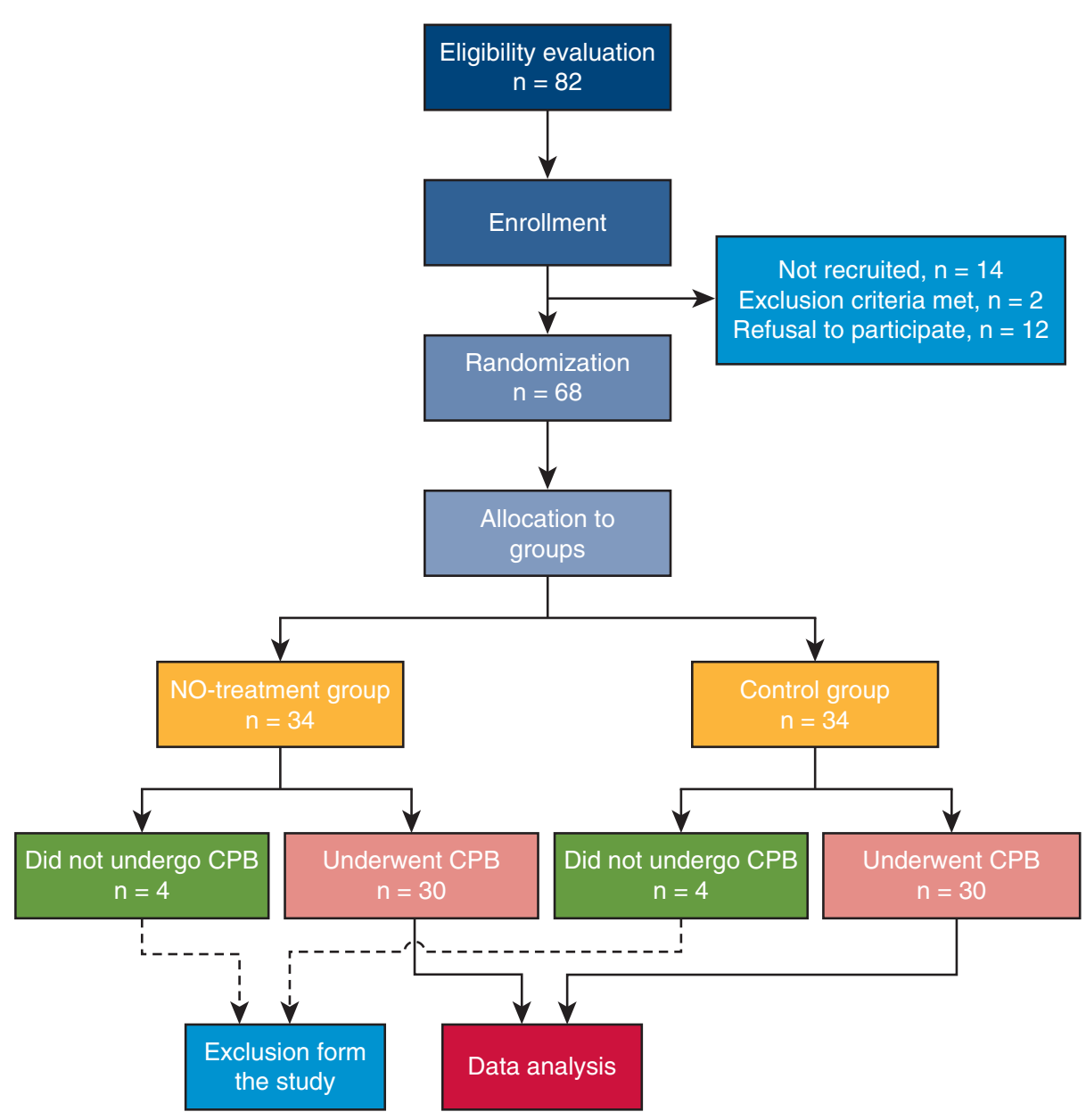

FIGURE 1. Consort diagram. $N O$, Nitric oxide; $C P B$, cardiopulmonary bypass.

was necessary in the sham-treatment group. The primary endpoint was change in cTnI. The secondary end points comprised CK-MB change and vasoactive inotropic score (VIS). We used a computer-generated permuted block (up to a size of 20 and 1:1 allocation) randomization sequence (http://sealedenvelope.com). Treatment allocation was prepared by an independent operator (research assistant) not otherwise involved in the trial and is concealed by opaque, sealed envelopes that were sequentially numbered. The Society of Thoracic Surgeons Risk Calculator was used for risk score assessment showing that the groups were comparable (Table E1). The general anesthesia procedure did not differ between groups. Trial participants, data analysts, and report writers were blinded.

Preoperatively, all patients received narcotic analgesic, benzodiazepine, and antihistamine premedication. Fentanyl (3.0-5.0 $\mu \mathrm{g} / \mathrm{kg}$ ) and propofol $(1.5 \mu \mathrm{g} / \mathrm{kg})$ were used to induce anesthesia. Pipecuronium bromide $(0.1 \mathrm{mg} / \mathrm{kg})$ was used for neuromuscular blockade. Anesthesia was maintained with inhalation of sevoflurane 2 to $3 \mathrm{vol} \%$ and infusion of fentanyl (3.0-5.0). Intraoperative mechanical ventilation was carried out with Primus (Draeger AG, Lübeck, Germany) using semiclosed line in controlled mandatory ventilation mode with controlled volume and concentration of oxygen in the inhaled mixture of $30 \%$ and greater depending on the clinical necessity, respiratory volume of 6 to $7 \mathrm{~mL} / \mathrm{kg}$, respiratory rate of 12 to 14 breaths per minute to maintain normocapnia, and positive end-expiratory pressure of 5 mbar.

CPB was performed in a nonpulsatile mode with a Stockert system (Stockert Inc, Freiburg, Germany) with disposable membrane oxygenators. The perfusion index was $2.8 \mathrm{~L} / \mathrm{min} / \mathrm{m}^{2}$. For the initial volume of CPB,
$500 \mathrm{~mL}$ of $4 \%$ modified gelatin solution (Gelofusine; B. Braun Melsungen AG, Melsungen, Germany) and $500 \mathrm{~mL}$ of balanced crystalloid solution (Sterofundin Iso; B. Braun Melsungen AG) were used. Tranexamic acid $(2 \mathrm{mg} / \mathrm{kg} / \mathrm{h}$ ) was used as an antifibrinolytic drug in all patients.

$\mathrm{CPB}$ connection was carried out following the standard technique according to the aorta-to-right atrium scheme. Heparin $(3 \mathrm{mg} / \mathrm{kg})$ was used before $\mathrm{CPB}$ in all patients; activated clotting time was maintained at the level of $>500$ seconds. Mean arterial blood pressure during CPB was maintained at 60 to $80 \mathrm{~mm} \mathrm{Hg}$; nasopharyngeal temperature was $35.5^{\circ} \mathrm{C}$ to $36.6^{\circ} \mathrm{C}$; and blood hemoglobin level was $\geq 80 \mathrm{~g} / \mathrm{L}$. Myocardial protection in both groups was achieved by perfusion of the ascending aorta or coronary artery (in cases of aortic insufficiency) with a cold $\left(5^{\circ} \mathrm{C}-8^{\circ} \mathrm{C}\right)$ crystalloid solution (Custodiol HTK-Bretschneider; Dr Franz Köhle rChemie $\mathrm{GmbH}$, Bensheim, Germany) at a dose of $3 \mathrm{~mL} / \mathrm{kg}$ for 6 to 8 minutes according to the manufacturer's instructions. Local hypothermia with ice gruel was used. Heparin was neutralized by administering protamine sulfate at a 1:1 ratio after the perfusion.

After surgery, all patients were transferred to the intensive care unit. The decision to perform off-pump CABG was made during the main stage of surgery in case of problematic aorta due to severe atheromatosis or calcinosis. In such cases, we had to eschew CPB requiring aortic clamping. Instead, off-pump surgery was performed with the use of both mammary arteries and composite grafting or the HEARTSTRING Proximal Seal System (Maquet, San Jose, Calif). Off-pump technology was also used if, after sternotomy, the surgeon defined anatomy of the coronary arteries as technically suitable for grafting without $\mathrm{CPB}$. 
In the NO-treated group, an additional NO supply line was connected to the gas-air mixture supply line under aseptic conditions. The NO supply line connector with a bacterial filter was as close as possible to the oxygenator of the CPB machine. Dosing of NO was carried out with the PrinterNOX analyzer (CareFusion, San Diego, Calif) to reach a target concentration of $40 \mathrm{ppm}$. The level of methemoglobin in peripheral blood was monitored by reflective photometry using the blood gas analyzer Stat Profile CCX (Nova Biomedical, Waltham, Mass). This protocol of NO supply was maintained during the entire $\mathrm{CPB}$ period. To avoid systemic hemodynamic effects, the time interval between the end of NO supply to the CPB machine and the weaning of patient from mechanical perfusion was 5 minutes.

Standard anesthesia monitoring was applied including continuous electrocardiography analysis, invasive monitoring of arterial pressure and vena cava pressure, pulse oximetry, and nasopharyngeal thermometry using the Infinity Delta XL monitor (Draeger AG). A central venous catheter (7F Certofix; B. Braun Melsungen AG) was placed into the right internal jugular vein. To monitor blood pressure and obtain blood samples for gas analysis, the radial artery was catheterized using a $20-\mathrm{G}$ arterial cannula (Arteriofix; B. Braun Melsungen AG). The bladder was catheterized for diuresis measurement. Metabolic parameters, acid-base status of the blood, and plasma ionogram $(\mathrm{pH}$ and concentrations of bicarbonate, lactate, glucose, sodium, potassium, and calcium ions) were monitored. The sedation level was controlled by bispectral index-monitoring and was maintained in the range of 40 to 60 .

Systemic hemodynamics were monitored continuously before, during, and after CPB with control points before sternotomy, after sternotomy, before applying a clamp to the aorta, after $\mathrm{CPB}$ disconnection, and when transferred to the intensive care unit.

The degree of intraoperative myocardium injury was assessed based on the changes in plasma cTnI concentration and activity of CK-MB during the first 48 hours. Blood samples for biochemical examination were taken at baseline and 6,24, and 48 hours after surgery. cTnI was assessed with Pathfast chemiluminescent enzyme immunoassay analyzer (Mitsubishi Chemical Medience Corp, Tokyo, Japan) and enzyme immunoassay kit. CK-MB activity was assessed after immunoinhibition at $37^{\circ} \mathrm{C}$ by $\mathrm{N}$-acetylcysteine-activated optimized ultraviolet tests with ABX Pentra C200 (Horiba, Ltd, Kyoto, Japan).

To assess vasoactive drugs and inotropic support, VIS was calculated as follows: (dobutamine $\mu \mathrm{g} / \mathrm{kg} / \mathrm{min} \times 1+$ dopamine $\mu \mathrm{g} / \mathrm{kg} /$ min $\times 1+$ milrinone $\mu \mathrm{g} / \mathrm{kg} / \mathrm{min} \times 10)+100 \times($ adrenalin $\mu \mathrm{g} / \mathrm{kg} /$ $\min +$ noradrenaline $\mu \mathrm{g} / \mathrm{kg} / \mathrm{min}+$ vasopressin $\mu \mathrm{g} / \mathrm{kg} / \mathrm{min}$ ). VIS values were calculated immediately as well as 6 and 24 hours after surgery.

Statistical processing of data was performed with STATISTICA 10 (StatSoft Inc, Tulsa, Okla). The Kolmogorov-Smirnov test was used to check normality of variable distribution. Quantitative values were expressed as mean \pm standard deviation in case of normal distribution or median and 25th and 75th quartiles if distribution was not normal. Quantitative characteristics were compared by a $t$ test for 2 independent samples (for normal distribution) and the Mann-Whitney $U$ test for 2 independent samples (if distribution was not normal). Values were considered statistically significant when $P$ was $<.05$. Sample-size calculation was performed and adjusted for non-normality using STATISTICA 10 . Power analysis was performed before the study based on primary end point. Based on the determined cTnI level (an increase in cTnI 6 hours after operation $>2.1 \mathrm{ng} / \mathrm{mL}$ ) of $67 \%$ and type I error of $10 \%$, a sample size of 60 was calculated to provide $80 \%$ power to detect a reduction in the event rate to 30 (Appendix E1).

\section{RESULTS}

After the exclusion of 14 patients, the remaining 68 patients were randomized: each group comprised 34 patients. All patients received the study treatment assigned according to randomization. Eight patients were excluded (4 patients from each group), as they did not receive CPB.
TABLE 1. Characteristics of the patients at baseline

\begin{tabular}{|c|c|c|c|}
\hline Characteristics & $\begin{array}{c}\text { NO group, } \\
\mathbf{n}=\mathbf{3 0}\end{array}$ & $\begin{array}{c}\text { Control group, } \\
\quad \mathbf{n}=\mathbf{3 0}\end{array}$ & $P$ \\
\hline Age, y & $61.5[56.8 ; 65]$ & $58[55 ; 6.3]$ & .061 \\
\hline Male, n (\%) & $25(83.3)$ & $21(70)$ & .226 \\
\hline BMI, $\mathrm{kg} / \mathrm{m}^{2}$ & $27.7[25.2 ; 32.2]$ & $28.0[24.4 ; 31.0]$ & .848 \\
\hline LVEF, \% & $57.5[50 ; 63.3]$ & $57[51.8 ; 62]$ & .988 \\
\hline Angina class, $\mathrm{n}(\%)$ & & & .174 \\
\hline I & 0 & $1(3.3)$ & \\
\hline II & $4(13.3)$ & $8(26.7)$ & \\
\hline III & $26(86.7)$ & $21(70)$ & \\
\hline NYHA I, n (\%) & $4(13.3)$ & $2(6.7)$ & .923 \\
\hline NYHA II, n (\%) & $23(76.7)$ & $25(83.3)$ & \\
\hline NYHA III, n (\%) & $3(10)$ & $3(10)$ & \\
\hline $\begin{array}{l}\text { History of myocardial } \\
\text { infarction, } \mathrm{n}(\%)\end{array}$ & $25(83.3)$ & $22(72.3)$ & .347 \\
\hline Hypertension, $\mathrm{n}(\%)$ & $11(36.7)$ & $9(30)$ & .329 \\
\hline Smoking, n (\%) & $13(43.3)$ & $14(46.7)$ & .795 \\
\hline EuroSCORE & $4[2 ; 4]$ & $3[2 ; 4]$ & .347 \\
\hline
\end{tabular}

Data are presented as median [25th; 75th percentile] or number of patients (percentage). $N O$, Nitric oxide; $B M I$, body mass index; $L V E F$, left ventricle ejection fraction; NYHA, New York Heart Association classification; EuroSCORE, European system for cardiac operative risk evaluation.

The baseline and intraoperative characteristics of patients were similar in both groups (Tables 1 and 2). Heart rate, mean blood pressure, and cava vena pressure were considered the main determinants of myocardial oxygen demand and important factors of ischemic trauma in the intraoperative period. These indicators were comparable in patients in the NO-treated and control groups (Table 3). Metabolic

TABLE 2. Characteristics of the intraoperative period

\begin{tabular}{lccc}
\hline \multicolumn{1}{c}{ Characteristics } & $\begin{array}{c}\text { NO group, } \\
\mathbf{n = 3 0}\end{array}$ & $\begin{array}{c}\text { Control group, } \\
\mathbf{n}=\mathbf{3 0}\end{array}$ & $\boldsymbol{P}$ \\
\hline $\begin{array}{l}\text { Cardiopulmonary bypass } \\
\text { time, min }\end{array}$ & $110[85.8 ; 137]$ & $116[88.8 ; 129.5]$ & .717 \\
$\begin{array}{l}\text { Aortic crossclamp } \\
\text { time, min }\end{array}$ & $73.5[56.3 ; 89]$ & $80[63.8 ; 96.5]$ & .340 \\
\hline $\begin{array}{l}\text { Mechanical ventilation } \\
\text { time, h }\end{array}$ & $8[7 ; 20]$ & $13[7 ; 18,3]$ & .297 \\
ICU length of stay, h & $44[42 ; 48]$ & $46[42 ; 51]$ & .063 \\
Mortality, n $(\%)$ & - & - & N/A \\
Hospital stay length, d & $8[5 ; 11]$ & $9[6 ; 12]$ & .071 \\
\hline Number of grafts, $\mathrm{n}(\%)$ & & & \\
3 & $8(26.7)$ & $6(20)$ & .728 \\
4 & $15(50)$ & $18(60)$ & \\
5 & $7(23.3)$ & $6(20)$ & \\
\hline
\end{tabular}

Data are presented as median [25th; 75 th percentile] or number of patients (percentage). $N O$, Nitric oxide; $I C U$, intensive care unit; N/A, not available. 
TABLE 3. Indices of hemodynamics in the intraoperative period

\begin{tabular}{lccc}
\hline \multicolumn{1}{c}{ Variable } & NO group, & Control group, & \\
$\mathbf{n}=\mathbf{3 0}$ & $\mathbf{n = 3 0}$ & $\boldsymbol{P}$ \\
\hline HR, beats/min & & & \\
Before sternotomy & $68[64 ; 73]$ & $70[65 ; 74]$ & .090 \\
After sternotomy & $82[78 ; 86]$ & $80[76 ; 84]$ & .082 \\
Before aortic crossclamping & $70[66 ; 74]$ & $72[64 ; 73]$ & .075 \\
End of CPB & $80[76 ; 83]$ & $78[74 ; 80]$ & .083 \\
End of operation & $78[75 ; 82]$ & $76[74 ; 80]$ & .061 \\
MAP, mm Hg & & & \\
Before sternotomy & $66[64 ; 69]$ & $64[60 ; 65]$ & .096 \\
After sternotomy & $76[70 ; 80]$ & $78[72 ; 82]$ & .088 \\
Before aortic crossclamping & $64[60 ; 70]$ & $65[62 ; 72]$ & .074 \\
End of CPB & $72[68 ; 76]$ & $70[66 ; 74]$ & .079 \\
End of operation & $67[63 ; 74]$ & $68[64 ; 73]$ & .092 \\
CVP, mm Hg & & & \\
Before sternotomy & $6[4 ; 7]$ & $6[3 ; 7]$ & .058 \\
After sternotomy & $4[3 ; 5]$ & $5[4 ; 6]$ & .065 \\
Before aortic crossclamping & $3[2 ; 5]$ & $2[2 ; 4]$ & .089 \\
End of CPB & $8[6 ; 9]$ & $7[5 ; 9]$ & .071 \\
End of operation & $4[3 ; 7]$ & $5[4 ; 8]$ & .064 \\
\hline
\end{tabular}

Data are presented as median [25th; 75 th percentile]. $N O$, Nitric oxide; $H R$, heart rate; $C P B$, cardiopulmonary bypass; $M A P$, mean arterial pressure; $C V P$, vena cava pressure.

parameters, blood acid-base status, and plasma ionogram were within the normal reference ranges. The methemoglobin level in NO-treated group did not exceed $1 \%$.

The cTnI values before surgery were comparable in the NO-treated and control groups $(P=.47)$. The level of cTnI reached its maximum at 6 hours after surgery in both groups, but it was significantly lower in NO-treated group compared with the control: $1.79 \pm 0.39 \mathrm{ng} / \mathrm{mL}$ versus

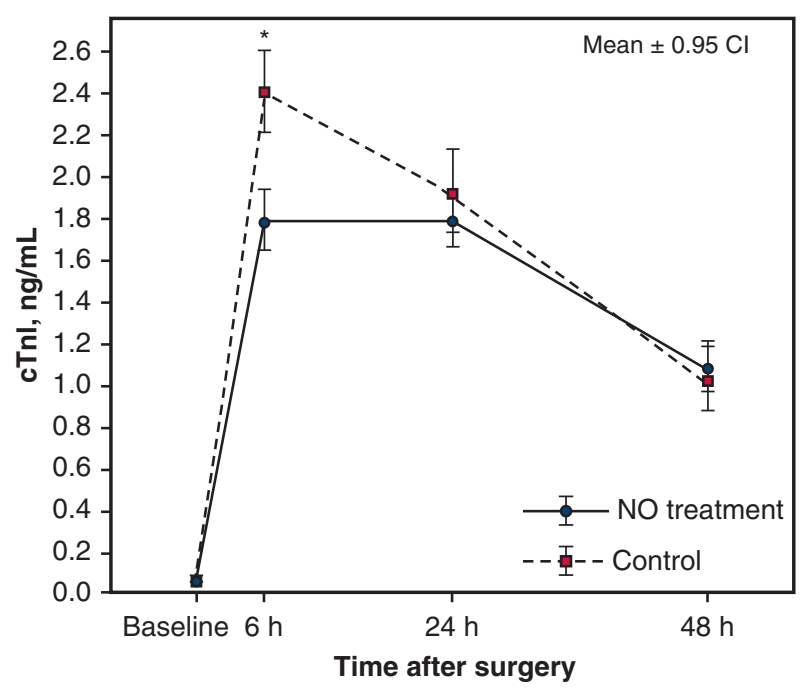

FIGURE 2. The levels of $\mathrm{cTnI}(\mathrm{ng} / \mathrm{mL})$ in the NO-treated and control groups within 48 hours after surgery, $P<.001, t$ test. $c T n I$, Cardiac troponin I; $N O$, nitric oxide; $C I$, confidence interval.
$2.41 \pm 0.55 \mathrm{ng} / \mathrm{mL}(P=.001$, statistical power of $>0.95)$ (Figure 2).

Initial CK-MB values were comparable in the NO-treated and control groups, $P=.80$. After the first 24 hours following surgery, the CK-MB level was significantly lower in the NO-treated group compared with the control: $47.69 \pm 8.08 \mathrm{U} / \mathrm{L}$ versus $62.25 \pm 9.78 \mathrm{U} / \mathrm{L}, P=.001$, statistical power of $>0.95$ (Figure $3, A$ ).

The VIS values 6 hours after surgery were $7.1 \pm 4.36$ in the NO-treated group and $13.9 \pm 4.75$ in the control group $(P=.001$, statistical power of 0.77 ) (Figure 3, B).

The complication rates did not differ between groups during the postoperative period (Table 4). Severe complications, such as myocardial infarction and stroke, did not occur in either group.

\section{DISCUSSION}

Ischemia-reperfusion injury of the myocardium in CABG patients is a universally recognized problem. However, no large clinical trials demonstrating the cardioprotective effects of $\mathrm{NO}$ or its precursors have been completed in this category of patients to date. Currently, only one clinical trial aimed at an evaluation of the protective role of nitrite in this category of patients is available (ClinicalTrials.gov NCT01098409). However, the end point of that study was the level of NO-synthase expression as an endogenous cytoprotective mechanism examined based on the left ventricular biopsies. The only available study on cardioprotective effects of native NO molecule supplied during and after $\mathrm{CPB}$ was performed by Gianetti and colleagues ${ }^{10}$ in a small number of patients receiving CABG with combined aortic valve replacement. Our study was performed in a larger number of patients undergoing isolated CABG surgery, which is an ideal model of ischemia-reperfusion injury because interventions combined with aortic valve replacement such as in the work of Gianetti and colleagues are associated with a mechanical trauma to the myocardium by a surgeon as well as with other factors, which are hard to predict and which can limit interpretations of the postoperative troponin I values. Isolated CABG together with an unbiased control of the quality of revascularization (based on flowmetry data) in our study allows to elucidate the impact of ischemia-reperfusion injury on the perioperative trauma of the myocardium. In addition, our study demonstrates, for the first time, a clinical significance of NOmediated cardioprotection preventing myocardial stunning and left ventricular dysfunction, as confirmed by a decrease in the need for inotropic support during the postoperative period (Figure 4). Certainly, the greatest beneficial effect of NO administration and more clinically relevant differences are expected in high-risk groups (in particular, in patients with attenuated pump function of the left ventricle). However, we believe it is relevant to ensure the efficacy 

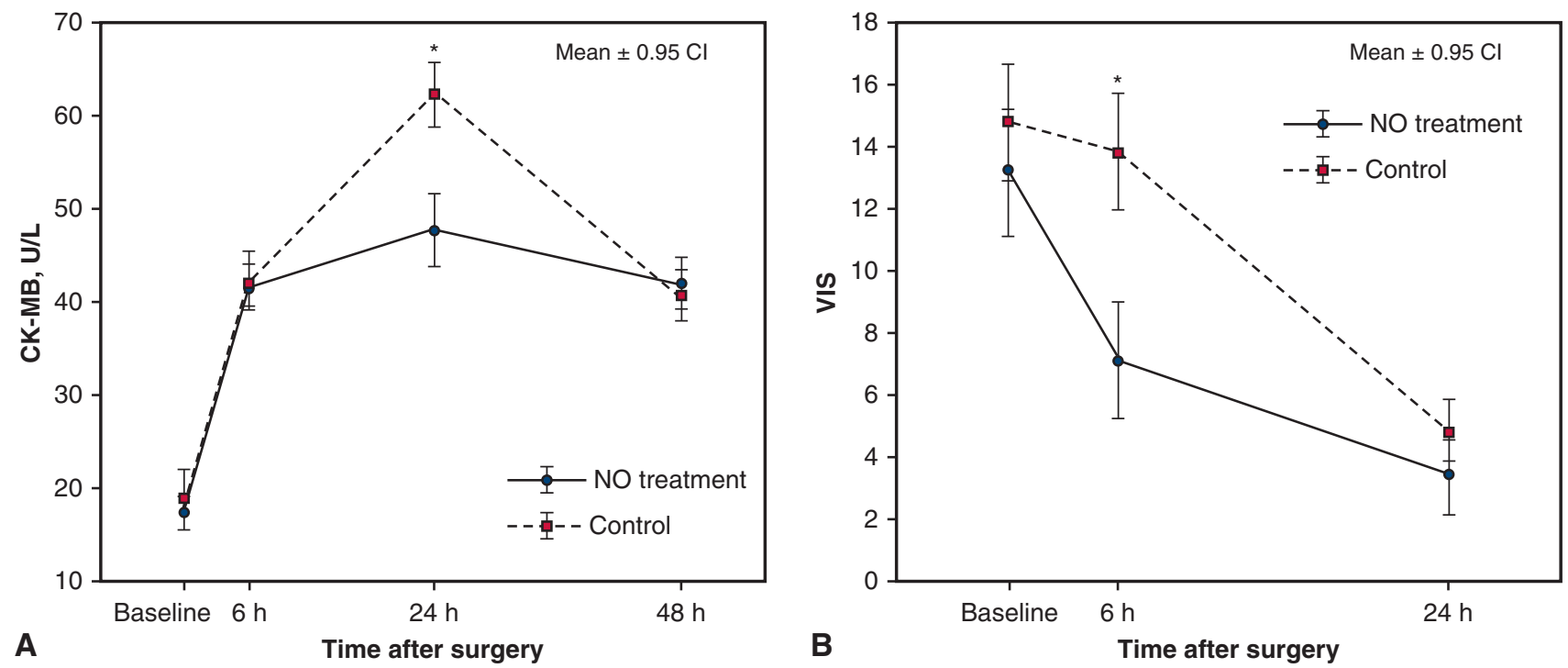

FIGURE 3. A, The levels of CK-MB (U/L) in NO-treated and control groups within 48 hours after surgery, $P<.001, t$ test. B, VIS values in NO-treated and control groups within 24 hours after surgery, $P<.001, t$ test. $C K-M B$, Creatine kinase-muscle/brain fraction; $N O$, nitric oxide; VIS, vasoactive-inotropic score; $C I$, confidence interval.

of this technology in our pilot study with a given cohort of patients.

The results of our study show the presence of cardioprotective properties of the exogenous NO supplied to the extracorporeal circulation line during myocardial revascularization. The major findings of our study comprise consistently lower levels of cTnI at 6 hours after surgery and a lower level of CK-MB at 24 hours after surgery in the NO-treated group. The results of recent studies indicate that NO and its signaling pathway play an essential role in the mechanisms of cardioprotection against ischemiareperfusion injury. $\mathrm{NO}$ is the most promising molecule of receptor-independent triggers and mediators of the preconditioning phenomenon. ${ }^{13}$ The gas has a number of properties exerting beneficial effects on ischemic myocardium. The literature suggests that direct cardioprotective action of NO may consist in the improvement of mitochondrial function of the cardiomyocytes, beneficial modulation of ion currents in the plasma membrane, and support of

TABLE 4. Structure and frequencies of complications

\begin{tabular}{lccc}
\hline \multicolumn{1}{c}{ Characteristic } & $\begin{array}{c}\text { NO group, } \\
\mathbf{n = 3 0}\end{array}$ & $\begin{array}{c}\text { Control group, } \\
\mathbf{n = 3 0}\end{array}$ & $\boldsymbol{P}$ \\
\hline Acute kidney injury, n (\%) & $1(3.33)$ & $3(10)$ & .309 \\
$\begin{array}{l}\text { Acute respiratory failure, } \\
\text { reintubation, n (\%) }\end{array}$ & $1(3.33)$ & 0 & .321 \\
$\begin{array}{c}\text { Acute respiratory failure, } \\
\text { pneumonia, n (\%) }\end{array}$ & 0 & $1(3.33)$ & .321 \\
$\begin{array}{l}\text { Delirium, n }(\%) \\
\text { Pneumothorax, n }(\%)\end{array}$ & $2(6.66)$ & $1(3.33)$ & .341 \\
\hline
\end{tabular}

Data are presented as number of patients (percentage). $N O$, Nitric oxide. electrical syncytium of the myocardium. These observations allow us to consider NO therapy a justified organ protection strategy in cardiac surgery.

Endothelial dysfunction during ischemia-reperfusion is associated with a decrease in NO production ${ }^{14}$ and endothelial damage causing dysregulation of vascular tone, prolonged vasoconstriction, and intravascular activation of leukocytes and thrombocytes. ${ }^{15}$ Endothelial dysfunction and NO deficiency worsen the left ventricular function and attenuate coronary blood flow during experimental ischemia-reperfusion in the presence of free hemoglobin. ${ }^{16}$ Therefore, it is essential to supply NO during the initiation of ischemia before clamping the aorta to provide reperfusion during parallel $\mathrm{CPB}$ to directly protect the myocardium. We hypothesize that systemic administration of NO may exert cardioprotective effects due to a release of putative bloodborn factors similar to those in remote preconditioning ${ }^{17}$ or due to neurally dependent mechanisms involved in this phenomenon. ${ }^{18}$ Moreover, neural and humoral remote cardioprotective factors may be codependent. ${ }^{19}$

The etiology of elevated troponin concentration in patients undergoing cardiac surgery is multifactorial and involves surgical manipulation, ischemia-reperfusion injury, suboptimal myocardial protection, and compartmentalization of systemic inflammatory response. ${ }^{20}$ At the same time, a number of authors state that postoperative troponin I level may be considered an indicator of the myocardial protection adequacy. ${ }^{21}$ Postoperative levels of troponin in adult cardiac patients are closely correlated with short-, medium-, and long-term mortality in this category of patients. $^{4,22}$ Even isolated increases in troponin I or in CK-MB are predictors of an unfavorable outcome. 


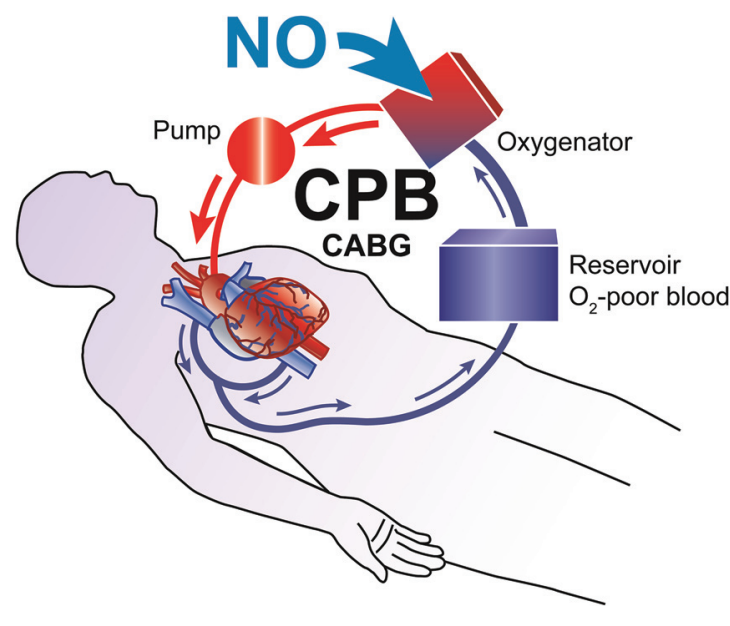

A

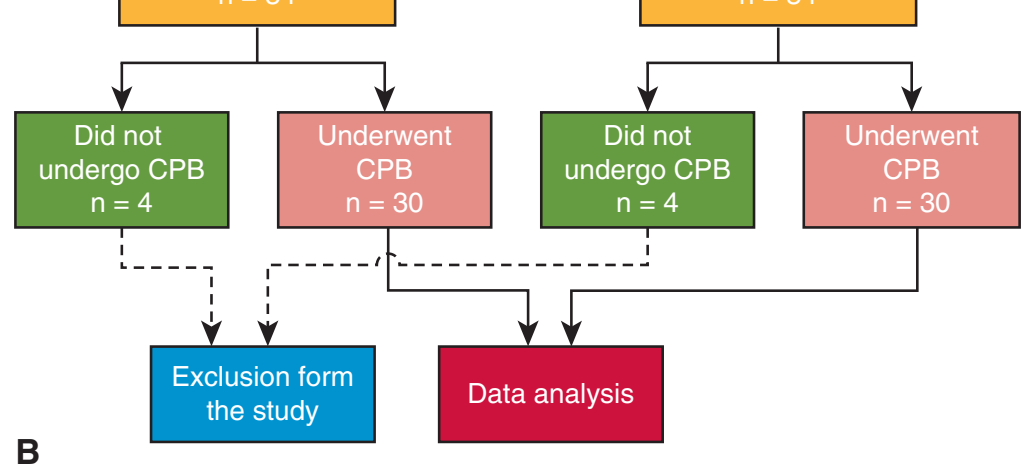

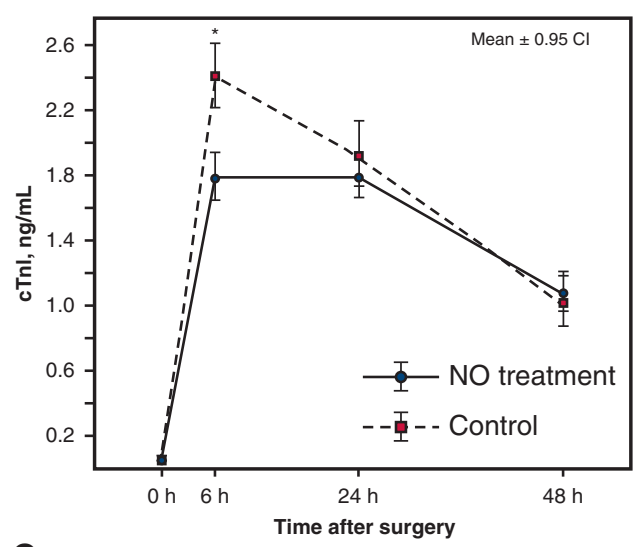

C
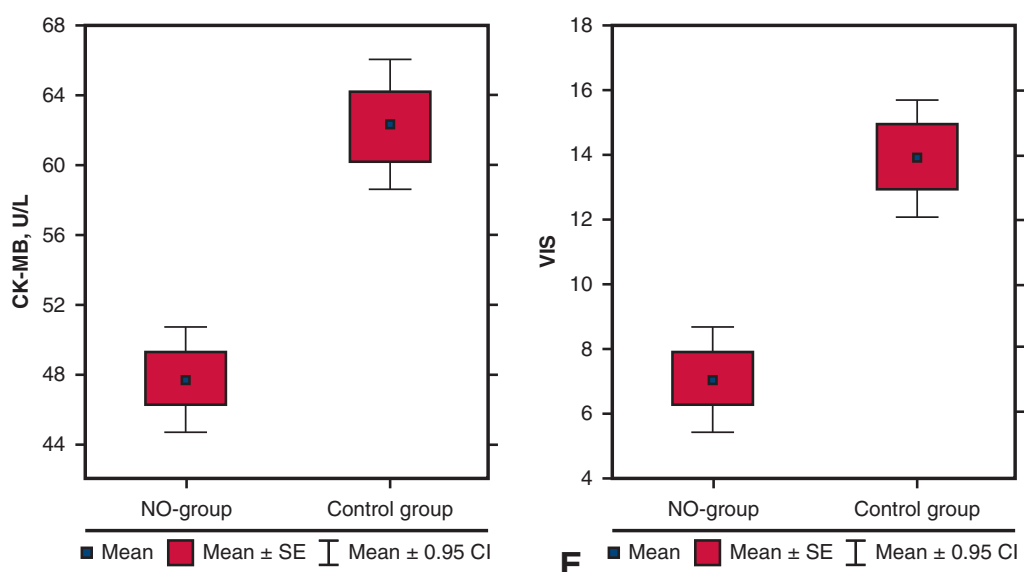

FIGURE 4. A, Scheme of nitric oxide $(N O)$ delivery to the oxygenator gas flow during coronary artery bypass grafting $(C A B G)$ with cardiopulmonary bypass $(C P B)$. B, Consort diagram. C, The levels of cardiac troponin I (cTnI, ng/mL) in NO-treated and control groups within 48 hours after surgery, $P<.001, t$ test. D, The levels of creatine kinase-muscle/brain fraction (CK-MB, U/L) in the NO-treated and control groups 24 hours after surgery, $P<.001, t$ test. E, Vasoactive-inotropic score $(V I S)$ values in NO-treated and control groups 6 hours after surgery, $P<.001, t$ test. $c$ TnI, Cardiac troponin I; $C I$, confidence interval; $C K-M B$, creatine kinase-muscle/brain fraction; $S E$, standard error. 
Although Beller and colleagues ${ }^{23}$ demonstrated that value of peak troponin after NSTEMI has no effect on surgical outcomes for $\mathrm{CABG}$, we believe that peak troponin after surgery is a relevant primary endpoint. In our study, the troponin level was low preoperatively in all cases. All patients underwent elective cardiac surgery. Myocardial infarction took place more than 6 months before operation. There were no urgent or emergent CABGs. The CPB time and crossclamp times were similar in the groups. The level of cTnI exceeded $2.1 \mathrm{ng} / \mathrm{mL}$ in control group 6 hours after surgery. After 48 hours, the level of cTnI returned to the baseline level. These data agree with the increased VIS value in the control group during the same period. Thus, we observe preservation of myocardial function in NO-treated group and assume developing myocardial injury in control group during the early postoperative period. We expect that, if used in a sicker patient population, NO treatment would reduce postoperative complication rate rather than just a peak troponin. This question requires further studies.

The second important finding was the greater level of inotropic and vasoactive drugs support in the early postoperative period in the control group. A lesser degree of VIS in the postoperative period (6 hours after surgery) was clinically observed in patients in the NO-treated group, suggesting a greater functional reserve of the myocardium and a lower probability of cardiac and noncardiac complications. ${ }^{24}$ The ability of NO molecule to modulate inflammatory response may contribute to improvement of clinical outcomes in cardiac and noncardiac surgery. ${ }^{10}$ Our results are consistent with data ${ }^{25,26}$ suggesting that NO, NOsynthase, and peroxynitrite are involved in antiarrhythmic effects of preconditioning. ${ }^{25}$ This is especially essential, considering that CPB use predicts the occurrence of postoperative atrial fibrillation. ${ }^{27} \mathrm{CPB}$ also is associated with the development of intravascular hemolysis and generation of free hemoglobin in the plasma, which severely limits the bioavailability of endogenous NO and provokes the development of organ dysfunctions with damage to the intestine and kidneys. ${ }^{10,28}$ Delivery of NO during CPB may alleviate inflammation in the heart and indirectly reduce secondary myocardial damage due to multiorgan dysfunction.

Unlike other researchers who studied cardioprotective effects of NO in adult cardiac patients, we used a very low dose of $\mathrm{NO}$ and administered it only for the period of the formation of the maximum NO-deficiency during CPB. Using this NO delivery method, we paid much attention to patient safety issues. We used a mixture of $\mathrm{N}_{2}$ with $\mathrm{NO}$ concentration of $200 \mathrm{ppm}$ as the source of NO. Thus, the maximum allowable fraction of inspired oxygen $\left(\mathrm{FiO}_{2}\right)$ for the use in $\mathrm{CPB} \mathrm{O}_{2} /$ air mixer was $80 \%$. It should be noted that such high $\mathrm{FiO}_{2}$ was not required in our study, and we used $50 \% \mathrm{FiO}_{2}$ on the average. Administration of $\mathrm{NO}$ according to the described procedure did not produce an increase in the $\mathrm{NO}_{2}$ concentration of more than $1.8 \mathrm{ppm}$.
NO leads to generation of methemoglobin; therefore, to avoid poisoning, it is required to monitor the blood level of methemoglobin carefully. In our study, methemoglobin content did not exceed $0.5 \%$ of total hemoglobin during $\mathrm{CPB}$, nor during the postperfusion period. The administration of NO in our study was not associated with any systemic hemodynamic effects; there were no intergroup differences between the numbers of patients requiring vasopressor drugs during $\mathrm{CPB}$ to maintain target blood pressure values.

Cost for NO treatment is an essential factor to consider, especially when $\mathrm{NO}$ is administered over a few days. The cost of $\mathrm{NO}$ administration in the operating room during CPB surgery is less substantial compared with NO inhalation lasting for days. ${ }^{29}$ At our institution, estimated cost of 40-ppm NO treatment was $\$ 70$. In literature, the reported cost of the NO is $\$ 6 / \mathrm{L} .{ }^{30}$ Depending on a patient's body weight and gas flow rate during $\mathrm{CPB}$, the cost of NO treatment may be within $\$ 100$ per procedure. Moreover, new cost-effective NO generators suitable for CPB are currently under development. ${ }^{29}$

This study has some limitations. In particular, it does not provide data regarding the optimal duration and titration dose of NO treatment as well as regarding the duration and dynamics of exposure to NO metabolites. The inclusion of patients with comorbidities could add a confounding variable in the study. Finally, the study had a short follow-up period and was lacking major adverse cardiac events that could better characterize the cardioprotective effects of NO administration. This work represents a pilot study based on data of biochemical myocardial injury markers and clinical examination and requires confirmation by larger interventional studies to verify the beneficial effects of $\mathrm{NO}$ administration in clinical settings involving ischemiareperfusion injury.

\section{CONCLUSIONS}

NO delivery to the extracorporeal circulation line during CABG with $\mathrm{CPB}$ exerted cardioprotective effects manifesting in decreased levels of cardiospecific markers and lower level of vasopressor and inotropic support required. Further randomized trials are needed to confirm the efficacy of NO treatment and to establish efficacious and safe doses and duration of NO therapy in cardiac surgery.

\section{Conflict of Interest Statement}

Authors have nothing to disclose with regard to commercial support.

\section{References}

1. Mebazaa A, Pitsis AA, Rudiger A, Toller W, Longrois D, Ricksten SE, et al. Clin-
ical review: practical recommendations on the management of perioperative
heart failure in cardiac surgery. Crit Care. 2010;14:201.
2. Tritapepe L, De Santis V, Vitale D, Guarracino F, Pellegrini F,
Pietropaoli P, et al. Levosimendan pre-treatment improves outcomes in 
patients undergoing coronary artery bypass graft surgery. $\mathrm{Br} J$ Anaesth 2009; 102:198-204

3. Yau JM, Alexander JH, Hafley G, Mahaffey KW, Mack MJ, Kouchoukos N, et al Impact of perioperative myocardial infarction on angiographic and clinical outcomes following coronary artery bypass grafting (from PRoject of Ex-vivo Vein graft ENgineering via Transfection [PREVENT] IV). Am J Cardiol. 2008;102: 546-51.

4. Bignami E, Landoni G, Crescenzi G, Gonfalini M, Bruno G, Pappalardo F, et al Role of cardiac biomarkers (troponin I and CK-MB) as predictors of quality of life and long-term outcome after cardiac surgery. Ann Card Anaesth. 2009;12:22-6.

5. Kupatt C, Hinkel R, von Brühl ML, Pohl T, Horstkotte J, Raake P, et al. Endothelial nitric oxide synthase overexpression provides a functionally relevant angiogenic switch in hibernating pig myocardium. J Am Coll Cardiol. 2007;49:1575-84.

6. Valdez LB, Bombicino SS, Iglesias DE, Rukavina-Mikusic IA, D’Annunzio V Mitochondrial complex I inactivation after ischemia-reperfusion in the stunned heart. In: Gelpi RJ, Boveris A, Poderoso JJ, eds. Biochemistry of Oxidative Stress: Physiopathology and Clinical Aspects. Book Series: Advances in Biochemistry in Health and Disease, Book 16. Cham, Switzerland: Springer; 2016:245-57.

7. Kruzliak P, Pechanova O, Kara T. New perspectives of nitric oxide donors in cardiac arrest and cardiopulmonary resuscitation treatment. Heart Fail Rev. 2014; 19:383-90.

8. Massoudy P, Zahler S, Freyholdt T, Henze R, Barankay A, Becker BF, et al. Sodium nitroprusside in patients with compromised left ventricular function undergoing coronary bypass: reduction of cardiac proinflammatory substances. $J$ Thorac Cardiovasc Surg. 2000;119:566-74.

9. Shinbo T, Kokubo K, Sato Y, Hagiri S, Hataishi R, Hirose M, et al. Breathing nitric oxide plus hydrogen gas reduces ischemia-reperfusion injury and nitrotyrosine production in murine heart. Am J Physiol Heart Circ Physiol. 2013;305: H542-50.

10. Gianetti J, Del Sarto P, Bevilacqua S, Vassalle C, De Filippis R, Kacila M, et al. Supplemental nitric oxide and its effect on myocardial injury and function in patients undergoing cardiac surgery with extracorporeal circulation. J Thorac Cardiovasc Surg. 2004;127:44-50.

11. Checchia PA, Bronicki RA, Muenzer JT, Dixon D, Raithel S, Gandhi SK, et al Nitric oxide delivery during cardiopulmonary bypass reduces postoperative morbidity in children - a randomized trial. J Thorac Cardiovasc Surg. 2013; 146:530-6.

12. James C, Millar J, Horton S, Brizard C, Molesworth C, Butt W. Nitric oxide administration during paediatric cardiopulmonary bypass: a randomised controlled trial. Intensive Care Med. 2016;42:1744-52.

13. Hataishi R, Rodrigues AC, Neilan TG, Morgan JG, Buys E, Shiva S, et al. Inhaled nitric oxide decreases infarction size and improves left ventricular function in a murine model of myocardial ischemia-reperfusion injury. Am J Physiol Heart Circ Physiol. 2006;291:H379-84.

14. Ma XL, Weyrich AS, Lefer DJ, Lefer AM. Diminished basal nitric oxide release after myocardial ischemia and reperfusion promotes neutrophil adherence to coronary endothelium. Circ Res. 1993;72:403-12.

15. Zahler S, Massoudy P, Hartl H, Hähnel C, Meisner H, Becker BF. Acute cardiac inflammatory responses to postischemic reperfusion during cardiopulmonary bypass. Cardiovasc Res. 1999;41:722-30.
16. Nemeto S, Aoki M, Dehua C, Imai Y. Free hemoglobin impairs cardiac function in neonatal rabbit hearts. Ann Thorac Surg. 2000;69:1484-9.

17. Gedik N, Kottenberg E, Thielmann M, Frey UH, Jakob H, Peters J, et al. Potential humoral mediators of remote ischemic preconditioning in patients undergoing surgical coronary revascularization. Sci Rep. 2017;7:12660.

18. Heusch G. Vagal cardioprotection in reperfused acute myocardial infarction. JACC Cardiovasc Interv. 2017;10:1521-2.

19. Pickard JM, Burke N, Davidson SM, Yellon DM. Intrinsic cardiac ganglia and acetylcholine are important in the mechanism of ischaemic preconditioning. Basic Res Cardiol. 2017;112:11

20. Takeda S, Nakanishi K, Ikezaki H, Kim C, Sakamoto A, Tanaka K, et al. Cardiac marker responses to coronary artery bypass graft surgery with cardiopulmonary bypass and aortic cross-clamping. J Cardiothorac Vasc Anesth. 2002 16:421-5.

21. Sadony V, Körber M, Albes G, Podtschaske V, Etgen T, Trösken T, et al. Cardiac troponin I plasma levels for diagnosis and quantitation of perioperative myocar dial damage in patients undergoing coronary artery bypass surgery. Eur J Cardiothorac Surg. 1998;13:57-65.

22. Lurati Buse GA, Koller MT, Grapow M, Bolliger D, Seeberger M, Filipovic M. The prognostic value of troponin release after adult cardiac surgery-a metaanalysis. Eur J Cardiothorac Surg. 2010;37:399-406.

23. Beller JP, Hawkins RB, Mehaffey JH, LaPar DJ, Kron IL, Yarboro LT, et al. Does preoperative troponin level impact outcomes after coronary artery bypass grafting? Ann Thorac Surg. 2018;106:46-51.

24. Yamazaki Y, Oba K, Matsui Y, Morimoto Y. Vasoactive-inotropic score as a predictor of morbidity and mortality in adults after cardiac surgery with cardiopul monary bypass. J Anesth. 2018;32:167-73.

25. Andelová E, Barteková M, Pancza D, Styk J, Ravingerová T. The role of NO in ischemia/reperfusion injury in isolated rat heart. Gen Physiol Biophys. 2005;24 411-26.

26. Szabó G, Loganathan S, Merkely B, Groves JT, Karck M, Szabó C, et al. Catalytic peroxynitrite decomposition improves reperfusion injury after heart transplantation. J Thorac Cardiovasc Surg. 2012;143:1443-9.

27. Akintoye E, Sellke F, Marchioli R, Tavazzi L, Mozaffarian D. Factors associated with postoperative atrial fibrillation and other adverse events after cardiac surgery. J Thorac Cardiovasc Surg. 2018;155:242-51.e10.

28. Vermeulen Windsant IC, Hanssen SJ, Buurman WA, Jacobs MJ. Cardiovascular surgery and organ damage: time to reconsider the role of hemolysis. J Thorac Cardiovasc Surg. 2011;142:1-11.

29. Qin Y, Zajda J, Brisbois EJ, Ren H, Toomasian JM, Major TC, et al. Portable nitric oxide (NO) generator based on electrochemical reduction of nitrite for potential applications in inhaled NO therapy and cardiopulmonary bypass surgery. Mol Pharm. 2017:14:3762-71.

30. Yang Y, Qia PK, Yang ZL, Huang N. Nitric oxide based strategies for applications of biomedical devices. Biosurface Biotribol. 2015;1:177-201.

Key Words: cardioprotection, ischemia-reperfusion injury, nitric oxide, cardiopulmonary bypass, coronary artery bypass grafting 
TABLE E1. Risk scores based on the Society of Thoracic Surgeons Risk Calculator

\begin{tabular}{|c|c|c|c|}
\hline Risks & $\begin{array}{l}\text { NO group, } \\
\mathbf{n}=\mathbf{3 0} \\
\end{array}$ & $\begin{array}{c}\text { Control group, } \\
\mathbf{n}=\mathbf{3 0} \\
\end{array}$ & $P$ \\
\hline Risk of mortality, $\%$ & $0.3 \pm 0.052$ & $0.29 \pm 0.49$ & .62 \\
\hline Morbidity or mortality, $\%$ & $5.1 \pm 0.14$ & $5.3 \pm 0.15$ & .58 \\
\hline Long length of stay, $\%$ & $1.4 \pm 0.033$ & $1.4 \pm 0.32$ & .71 \\
\hline Short length of stay, $\%$ & $75.6 \pm 0.43$ & $77 \pm 0.53$ & .69 \\
\hline Permanent stroke, $\%$ & $0.4 \pm 0.061$ & $0.42 \pm 0.06$ & .72 \\
\hline Prolonged ventilation, $\%$ & $3.35 \pm 0.11$ & $3.28 \pm 0.098$ & .68 \\
\hline DSW infection, $\%$ & $0.2 \pm 0.031$ & $1.9 \pm 0.04$ & .67 \\
\hline Renal failure, $\%$ & $0.3 \pm 0.042$ & $0.32 \pm 0.044$ & .75 \\
\hline Reoperation, \% & $2.6 \pm 0.038$ & $2.5 \pm 0.036$ & .68 \\
\hline
\end{tabular}

Risk model and variables were obtained from the Society of Thoracic Surgeons Adult Cardiac Surgery Database, Version 2.81. Procedure: coronary artery bypass only. NO, Nitric oxide; $D S W$, deep sternal wound.

\section{APPENDIX E1. SAMPLE SIZE CALCULATION}

Main outcome variable was presence or absence of troponin increase in the given titer in the early postoperative period. Value of significant differences was $37 \%$ or 0.37 (ie, $67 \%$ $30 \%$ ). Significance level was 0.05 . Power was $80 \%$. Test was 2-sided. Equation for the calculation of sample size for comparison of 2 event rates was as follows:

$$
\mathrm{N}=[\mathrm{A}+\mathrm{B}]_{2} \times\left[\left(\mathrm{p}_{1} \times\left(1-\mathrm{p}_{1}\right)+\left(\mathrm{p}_{2} \times\left(1-\mathrm{p}_{2}\right)\right)\right] /\left[\mathrm{p}_{1}-\mathrm{p}_{2}\right]^{2}\right.
$$

where

$\mathrm{N}$ was a sample size for each group

$\mathrm{p}_{1}$ was the first event rate $(0.67$ in the given case)

$\mathrm{p}_{2}$ was the second event rate ( 0.30 in the given case)

$\mathrm{p}_{1}-\mathrm{p}_{2}$ was clinically significant difference $(0.37$ in the given case)
A was a table indicated value depending on significance level (1.96 in the given case)

$\mathrm{B}$ was a table indicated value depending on power $(0.84$ in the given case) ${ }^{\mathrm{E} 1}$.

Substitution of the values to the equation gave:

$$
\begin{aligned}
\mathrm{N} & =[1.96+0.84]^{2} \times[(0.67 \times 0.33+(0.30 \times 0.7))] /\left[0.37^{2}\right] \\
& =24.7
\end{aligned}
$$

Therefore, each group had to comprise at least 25 subjects. Considering a possible $20 \%$ dropout rate, sample size was increased to 30 patients in each group.

\section{E-Reference}

E1. Bland M. An Introduction to Medical Statistics. 3rd ed. Oxford: Oxford University Press; 2000. 